\title{
EDUCAÇÃO, PARADIGMAS E TENDÊNCIAS: POR UMA PRÁTICA EDUCATIVA ALICERÇADA NA REFLEXÃO
}

\author{
Liliana Soares Ferreira \\ Faculdade Três de Maio, Brasil
}

\section{INTRODUÇÃO}

Propor-se a uma compreensão da educação implica atribuir sentidos às falas de seus protagonistas sobre o cotidiano. Professores, alunos, comunidade escolar lêem, na educação, aspectos significativos em acordo com sua perspectiva cultural. Ouvindo estas falas, muitas delas exaltando o caótico, genericamente, chega-se à idéia de problemas. Ao mesmo tempo, o discurso sobre o presente é afetado pela premissa de que se vive sucessivas crises. A concepção de crise aqui tem um sentido negativo, fornece a ilusão de caos, de perda do significado, de fim. Fala-se muito em crise na educação. No entanto, parece mesmo que a crise não é exatamente na educação, mas de como se pensa a educação. A crise parecer ser, portanto, uma crise de racionalidade. Isto acontece porque refletir sobre a educação atual não é tarefa das mais fáceis em uma época caracterizada pela diversidade de pensamentos, paradigmas, ações. Vive-se a heterogeneidade das abordagens sociais, das leituras de mundo, o esfacelamento das grandes teorias que explicaram as formações sociais até agora. A sensação é de caos, de generalidades, de falta de ancoradouro e de explicações totalizantes até então consideradas capazes de serem obtidas. Cabe, então, refletir sobre como se chega a esta forma de racionalidade, compreendendo-a não como única, mas por ser diversa, em acordo com a multiplicidade de saberes possibilitados pela multiplicidade de abordagens que nossos tempos dispõem.

Em um mundo onde se tem acesso a tantas e variadas informações e onde é possível até mesmo conhecer aspectos de outras culturas, manter contato facilmente com elas e assim ser influenciado, recebese também inúmeras informações sobre processos educativos. Há, diariamente, possibilidades infindas de se conhecer estudos, propostas, práticas e projetos educativos oriundos das mais diversas culturas. Esta facilidade de acesso às outras culturas e às outras práticas educativas impõe responsabilidades: como selecionar o que é produtivo e possível de ser estudado na realidade imediata, em acordo com os pressupostos orientadores das práticas educativas no cotidiano? Que critérios precisam orientar a seleção e quais referências paradigmáticas os sustentam? Advém daí a necessidade de se ter clareza quanto às diversas possibilidades de entender a educação. Esta clareza pode ser garantida pelas diferentes áreas do conhecimento e pelas leituras apresentadas da educação sob a perspectiva de organizá-la em tendências e paradigmas.

Propõe-se, a seguir, uma leitura destas tendências e paradigmas. Obviamente, esta leitura é oriunda de uma tentativa de atribuir significados à questão, estando sujeita, portanto, a análises diversas. $\mathrm{Na}$ verdade, o que orienta esta proposta é a necessidade, há muito sentida, de organizar roteiros de compreensão mais sintéticos, capazes de auxiliar os colegas da área de educação no momento de dar início aos seus estudos, indicando começos nos quais identifiquem as primeiras categorias possíveis. É 
claro que, por ser a educação esta complexidade e estar tão relacionada a tantas áreas, não se ignora ser esta uma proposta talvez até simplificadora. No entanto, é preciso começar por uma proposta, que a ela se associem outras interpretações e talvez se possa compreender melhor os pressupostos orientadores da educação nos dias atuais. Assim, é preciso entender este texto como uma espécie de chave de leitura a ser enriquecida com outras leituras. Aqui está o começo, a continuidade fica a cargo do interesse por este ou aquele rumo de leitura.

\section{TENDÊNCIAS E PARADIGMAS}

Qualquer prática ou estudo em educação precisa deixar claro, desde o início, as categorias que o orientam. Definir estas categorias remete o autor a classificações, a apegos a determinadas linhas de pensamento. São estas linhas as definidoras dos rumos a seguir, por isto representam racionalidades: a forma como se pensa a educação. Assim, partindo-se do pressuposto que toda a ação educativa implica necessariamente uma intencionalidade, porque é uma ação política, é preciso ter o entendimento destas racionalidades para, a partir daí, movimentar-se. Importante destacar que este processo só acontece no coletivo, referenda-se e consubstancia-se no grupo de professores, momento e espaço propício para a necessária reflexão e para a distinção entre as diferentes possibilidades orientadoras do fazer educativo.

Faz-se necessário, no entanto, ter claro que não existe linha pedagógica totalmente original. Dada a diversidade de pesquisas na área, a história da educação rica em possibilidades teóricas e em relato de práticas educativas múltiplas e sabendo-se que as práticas hoje são a síntese de muitas outras práticas dialeticamente constituídas, não há como se pensar que, em uma sociedade globalizada também do ponto de vista do conhecimento, haja originalidade absoluta. Original é a re-leitura feita desta história e a forma como se pode adequá-la a nossa realidade compondo, então, uma prática da comunidade escolar.

Entende-se por tendência toda e qualquer orientação de cunho filosófico e pedagógico que determina padrões e ações educativas, ainda que esteja desprovida de uma reflexão e de uma intencionalidade mais concreta. Uma tendência pedagógica é, na verdade, uma inclinação por pensamentos e comportamentos pedagógicos lidos na história da educação ou mesmo em outras práticas pedagógicas hodiernas. Muitas vezes, em uma escola, em uma comunidade, percebem-se práticas educativas cuja orientação embora existente não é fruto de uma reflexão mais apurada, consensada. Assim, vão-se reproduzindo e tornam-se explicações do processo educativo, enraizando-se na dinâmica escolar. Por seu caráter provisório, já que demandam uma maior reflexão, estas orientações são consideradas tendências. Se fruto de análise, de pesquisas, de estudo passam desta configuração ao status de uma teoria, de uma proposta educativa.

Os paradigmas, por sua vez, apresentam-se mais definidos enquanto orientadores de práticas educativas porque se apresentam como idéias e pressuposições muito bem delineadas, estudadas e teorizadas. Constituem-se em estruturas mais gerais e determinantes não só da forma de conceber a educação, mas da forma de agir educacionalmente. Acabam por condicionar e determinar todo o pensamento, as ações, as propostas de um determinado momento histórico. Mario Osorio Marques tem 
apresentado em sua obra uma possibilidade de compreensão de paradigmas que explica a diferenciação que ora fazemos:

Os paradigmas básicos do saber, que se sucederam interpenetrados e que continuam em nossa cultura e em nossas cabeças, necessitam recompor-se em um quadro teórico mais vasto e coerente. Sem percebê-los dialeticamente atuantes, não poderemos reconstruir a educação de nossa responsabilidade solidária. (Marques, 1993, p. 104)

Este autor, no conjunto de sua obra mais recente, refere-se à idéia de paradigma considerando a obra de Habermas (especialmente as proposição deste autor de uma racionalidade capaz de contrapor à racionalidade instrumental característica do Positivismo, uma racionalidade cuja essência é a linguagem) e ratifica a idéia que os paradigmas são um conjunto de concepções presentes em uma determinada época, configurando o modo de pensar dos seres humanos e a forma como estes conhecem o mundo, em permanente construção histórica.

Paradigmas são, portanto, um conjunto de conceitos interrelacionados de tal forma a ponto de proporcionar referenciais que permitem observar, compreender determinado problema em suas características básicas: o quê, como, o que se pretende observar e orientar possíveis soluções. É um conjunto conceitual que garante a coerência interna de qualquer proposta na área da educação e articulação entre o que se faz e o que se pensa, permitindo ao professor agir intencionalmente. Ao educador cabe fazer distinção entre paradigmas para que se perceba as alternâncias no pensamento educacional ao longo da história e, da mesma forma, se perceba quais idéias são relevantes, quais são desconsideradas e em que época o são e por quê. É sob esta perspectiva, o movimento em educação: de posse do conhecimento de determinados paradigmas, que se busca encaminhar os processos educativos, mas, para tanto, faz-se necessário reflexão, entender quais paradigmas são os orientadores e por que o são.

Desta forma, uma análise da vida escolar ao nosso redor, sob o ponto de vista das orientações que determinam a prática educativa nos remete a identificarmos tendências ou paradigmas consciente ou inconscientemente determinantes na linguagem, nas ações, nos instituídos garantindo esta ou aquela configuração escolar. Entender esta configuração é deslindar estes pressupostos, compreendendo-os em seu momento e nas determinações históricas que os configuraram.

Para tanto, é necessário que o professor defina suas ferramentas teóricas, estabeleça pontos de referências com os quais poderá exercer sua dimensão hermenêutica: atribuir sentidos, produzir interpretações do que vive nas ações pedagógicas desenvolvidas, inserindo-as em uma vertente teórica e tendo condições de propor a continuidade de uma reflexão-ação sobre seu projeto educativo. Vale dizer: ao educador cabe analisar informações e teorias, construir um todo de conhecimentos sólidos para fundamentar suas práticas pedagógicas. Na verdade, ao educar, o educador já está produzindo uma prática geradora de uma teoria pedagógica, posto que esta constitui aquela, de forma a não se saber onde começa uma e onde acaba a outra. Pensando assim que se propõe, a seguir, uma leitura de algumas tendências e paradigmas orientadores das práticas educativas, tais como são lidas na realidade. 


\section{SOB O PONTO DE VISTA DA PSICOLOGIA}

Considera-se, inicialmente, a Psicologia. Ciência relativamente nova, assumiu, no século $X X$, importância decisiva nos estudos em qualquer área das ciências humanas, pois permitiu dimensionar o ser humano, a pesquisa e a sociedade com base em compreensões mais elaboradas da constituição psíquica e em explicações dos comportamentos à luz do intrapsiquismo. A título de exemplificação, basta citar os revolucionários estudos de Freud e de Lacan, no início do século. Após suas teorias, todas as ciências agregadas à Psicologia tomaram rumos diferenciados, redefiniram conceitos básicos e propuseram ampliadas abordagens sobre a vida humana.

Em termos de relação que os sujeitos estabelecem com os objetos do conhecimento, a Psicologia apresenta três grandes paradigmas. A características básica entre eles é a relação que o sujeito-aprendente estabelece com o aprendido. Na forma como interagem, prevê-se a aprendizagem, a saber:

a) $S \hookleftarrow \quad O$ : É a idéia difundida pelos defensores do empirismo e do comportamentalismo. O comportamentalismo está inserido na tradição das investigações empiristas em psicologia e pressupõe que a aprendizagem é a mudança de comportamento resultante do treino ou da experiência, já que é o meio ou o objeto que determina o sujeito. Na base destas duas propostas está a concepção de que o objeto é apreendido pelo sujeito.

b) $S \not D$ : Esta é a proposição cujo alicerce é a idéia que o sujeito já possui a capacidade de conhecimento do objeto de aprendizagem. Para que este conhecimento se efetive é preciso que o sujeito aja sobre o objeto, internalizando-o. O alicerce é a idéia que o sujeito já pressupõe um conhecimento anterior sobre o objeto, manipulando-o, lidando com ele, reconfigurando-o sensoriamente. O conhecimento é, portanto, anterior à aprendizagem. Ao lidar com os objetos, os sujeitos vão tornando-os conhecidos e podem constituí-los como conhecimentos. É a idéia defendida pelo inatismo e pelo não-diretivismo, embasada na concepção que o sujeito determina o objeto. Há um primado absoluto do sujeito sobre o objeto do conhecimento.

c) $\mathrm{S} \Leftrightarrow$ O: O sujeito age em relação ao objeto, apreende-o e aprende sobre si próprio. Há uma inter-relação com vistas ao conhecimento. Do ponto de vista epistêmico, associa-se este posicionamento ao construtivismo e ao interacionismo. Para o construtivismo o conhecimento é construído, na sua forma e conteúdo, por um processo de interação entre sujeito e meio, processo ativado pela atividade do sujeito e estimulado pelo meio. Pode-se afirmar que o construtivismo proposto por Piaget se insere em uma posição integradora entre o empirismo e o racionalismo, pois, para de, o conhecimento depende de construções sucessivas com a elaboração de estruturas novas, em uma linearidade evolutiva. Se, por um lado, o construtivismo apresenta-se como a perspectiva de caráter epistemológico cuja base é a percepção de que o ser humano, ser cognitivo, desenvolve sua inteligência reelaborando estruturas mentais hierarquicamente construídas, por outro, até de uma forma a superar esta postura, o interacionismo propõe a mediação como o elemento desestruturante, possibilitador de o sujeito, em interação com outros sujeitos, utilizando a linguagem, produzir saberes. O interacionismo pressupõe que o indivíduo interioriza a cultura, a natureza e, progressivamente, torna-se autônomo, cada vez mais apto a utilizar a linguagem em favor da produção de seu conhecimento.

O divisor de águas entre esta terceira concepção e as anteriores reside no aspecto caracterizador da relação sujeito e objeto de conhecimento. Nas duas primeiras, este objeto é o ponto convergente, o sujeito age no intuito de obter o conhecimento relacionando-se com este objeto. Na terceira concepção, insere-se a ação e a linguagem como as formas de produção do conhecimento. Sobretudo a linguagem gera uma mudança na concepção de aprendizagem, pois passa-se de uma idéia de unidade, de saber único, para a possibilidade de se recriar o saber e até mesmo o objeto a ser conhecido por meio da linguagem. No processo de aprender, também aquele que aprende vai reconfigurando-se, como uma metalinguagem, ao aprender sobre o outro aprende sobre si. 


\section{SOB O PONTO DE VISTA DA FILOSOFIA DA EDUCAÇÃO}

A Filosofia da Educação pretende uma teorização do fazer educativo, compreendendo de forma crítica e reflexiva a racionalidade que orienta as ações pedagógicas. Nas palavras de Prestes:

A filosofia da educação é um tipo de saber globalizante compreensivo e crítico do processo educacional, que envolve a explicitação dos pressupostos que justificam a ação pedagógica. Nesse sentido, a filosofia da educação ilumina questões que se tornam obscurecidas pela dificuldade de superar contradições reinantes no campo educativo, quando os velhos fundamentos metafísicos perdem seu vigor explicativo para justificar a formação de identidade pessoal e cultural dos sujeitos. (1996, p.15)

Em relação à Filosofia da Educação, encontra-se, com base em concepções de mundo e de ser humano delineadas em sucessivas alterações possibilitadas pela superação de uma corrente filosófica em relação a outras, três paradigmas básicos, capazes de levar à reflexão de como as pessoas concebem o conhecimento e as relações implicadas no ato de conhecer, ao longo da História, a saber:

a) Paradigma ontológico: implica em um enfoque objetivo, pois visa à descoberta das essências. 0 conhecimento precisa ser tornado consciente, o aprendiz precisa descobrir que sabe, apreender o objeto, pois é o objeto que determina o sujeito.

b) Paradigma moderno: há um enfoque subjetivo, pressupondo que a consciência constrói a realidade e a ciência da natureza é a referência para esta construção. A subjetividade coordena o processo de aprender e o sujeito determina o conhecimento.

c) Paradigma da comunicação: pressupõe o diálogo, o consenso, há, portanto, um enfoque intersubjetivo. Para que se produza o conhecimento é preciso considerar-se uma comunidade de sujeitos competentes lingüisticamente que se comunicam sobre seus mundos e chegam a consensos, saberes.

Quanto ao Paradigma Ontológico, ressalta a predominância da forma grega de pensar destacando a concepção de conhecer como inserção daquele que aprende na ordem do mundo. Para tanto, a escola desempenha o papel de lugar central para o acesso à verdade estabelecida.

De uma forma de pensar assim simplificada remonta esta visão da Escola como algo para além das fronteiras da vida. Um espaço reservado aos que podem freqüentá-la e, sobretudo, aos que conseguem progredir em seu interior. (Ferreira, 2001, p.153)

Como prerrogativa, em uma escola desta forma configurada, educar é transmitir fielmente as verdades estabelecidas como imutáveis e aprender é a assimilação passiva das verdades ensinadas, uma vez que o conhecimento está pronto, não precisa ser ressignificado, apenas aprendido. Ensinar é repetir, aprender é memorizar. Ensinar é função do professor, que detém o conhecimento, aprender é função do aluno que ignora o saber. Os métodos resumem-se à exposição, à memorização, à repetição e a avaliação assemelha-se a um juízo de valor, contabilizando os erros e os acertos.

Compõe a concepção de Paradigma da Modernidade a idéia de que o homem cria seu próprio universo científico separado do universo moral. Estes universos são dimensionados por uma racionalidade individual que tudo controla e coordena. Para conhecer, o ser humano precisa constituir os objetos, transformá-los, representá-los. Daí porque este conhecimento é sempre em fragmentos (origem da divisão escolar em séries e em componentes curriculares e da divisão do ser humano em ser dotado de aspectos cognitivos, afetivos e psicomotores). Esta postura justifica-se por ser representativa da estrutura social e o ser humano vai à escola para preparar-se para o desempenho de uma função social. 
Encontram-se referências que ajudam a entender melhor o Paradigma da Comunicação na obra de Jürgen Habermas. Na verdade, a área educacional muito pode (e pôde) se aproveitar das idéias de Habermas em suas obras sobre a teoria do agir comunicativo. Isto acontece porque jamais se teve tanta necessidade de redefinir as perspectivas pedagógicas com o intuito de acompanhar um tempo de sucessivas alternâncias conceituais. A ação comunicativa é profícua em se tratando de uma possibilidade de se pensar e encaminhar a educação, tendo em vista que se volta para o cerne da prática pedagógica: a prática da linguagem por sujeitos constituídos. Nesta esfera, o conhecimento surge do convívio com os objetos, com os instrumentos e com as pessoas. A educação é um processo interativo e a escola é o espaço para este entendimento compartilhado entre sujeitos organizados que, na aula, têm lugar para o encontro, para o estabelecimento de relações educativas viabilizadas através da linguagem, componente básico que permite a interação. É evidente que o conceito de educação que está pressuposto aqui é de ser uma ação interativa entre sujeitos. Educação implica sempre em interação: pela linguagem, os sujeitos se entendem e, juntos, entendem o mundo.

\section{SOB O PONTO DE VISTA DA PEDAGOGIA}

Em todo o lugar onde houver convivência, interação entre sujeitos, estão sendo produzidos saberes. Por isto, a Pedagogia é uma forma de compreender a educação para além das paredes do prédio escolar e o aprender é um processo que acontece sob a forma de relações em espaços diferentes, nos quais o sujeito estabelece conexões entre sua subjetividade e o ambiente, produzindo, assim, saberes. Portanto, tem-se a Pedagogia não apenas como uma possibilidade de reflexão acerca do processo educativo nas suas dimensões sociais, históricas, filosóficas e instrumentais.

A partir da Pedagogia, constituída como ciência do educador, poder-se-ia organizar todas as tendências pedagógicas como orientadas por uma das duas possibilidades a seguir:

diretividade: quando há uma ação intencional que vise a produzir resultados de aprendizagem, normalmente protagonizada pelo professor. Neste espaço, o aluno é aquele que precisa aprender e só aprenderá se submetido às orientações do professor.

não-diretividade: quando não há uma orientação anterior, mas produzem-se orientações em acordo com a vontade e os objetivos do aprendente. Neste caso, não há primazia do professor em relação ao aluno, ambos estão na condição de aprendentes.

Observando a história da educação no Brasil e com base nestas duas possibilidades surge a classificação das correntes pedagógicas proposta a seguir:

a) Pedagogia Tradicional: esta forma pedagógica está enraizada na história da educação brasileira desde os jesuítas, cristalizando-se quando, no final do século XIX, chegam as idéias de Herbart. Sua essência diz respeito ao magistrocentrismo: o professor sabe e o aluno não sabe, mas com o auxílio, a orientação e os métodos propostos pelo professor pode vir a saber. Preocupa-se também com a moralização dos sujeitos.

b) Pedagogia Nova: as idéias da Escola Nova chegam ao Brasil na segunda metade do século XX, propondo uma pedagogia que se contrapõe diretamente à Pedagogia Tradicional, na medida em que centraliza toda prática pedagógica no aluno, respeitando-o como capacitado a aprender desde que aja, produza ações. Delimitam-se nesta perspectiva todas as pedagogias progressistas surgidas no século XX: a Pedagogia Libertária, a Pedagogia Libertadora e a Pedagogia Crítico-social dos conteúdos. 
c) Pedagogias críticas: surgidas nas duas últimas décadas e fruto de muitos estudos e teses, constituem em estudos sobre o currículo enquanto recorte da sociedade levado para a escola. Visam à proposta de uma escola que reflita sobre as composições societárias visando à emancipação dos sujeitos a partir de suas aprendizagens. Nesta corrente, filia-se a pedagogia histórico-crítica.

Já se sabe que um espaço pedagógico eminentemente diretivo acaba por impedir a circulação da liderança e a constituição da autonomia. Quando só o professor tem direito de fala e o exerce de forma coercitiva não permite a mais ninguém a livre manifestação de idéias, interesses, o revelar da historicidade. Em uma época como a nossa, de liberdades inúmeras, manter esta postura é ser, no mínimo, incoerente e compactuar com a mediocrização dos sujeitos. O conhecimento produz-se em situações de transferência e, para tanto, faz-se necessária a liberdade de expressão, de ação, o diálogo.

A não-diretividade, por sua vez, precisa também estar embasada em alguns suportes, como o respeito, o espaço para sistematização, a produção coletiva. Quando, em uma sala de aula, confunde-se não-diretividade com ausência de regras ou o adulto infantiliza-se, o resultado é a não-produção de conhecimentos, pois para esta acontecer é preciso, projeção no outro daquilo que eu desejo.

\section{COERÊNCIA E CONCEPÇÕES}

A elaboração de quaisquer planejamentos ou mesmo a explicitação das orientações determinantes dos processos pedagógicos precisa estar alicerçada em uma base de coerência. Esta base, metaforicamente, é como um grande guarda-chuva protetor e sustentador de todo o processo, ao qual o professor pode recorrer sempre, para justificar suas ações e encaminhamentos. Faz parte desse conjunto de idéia a determinação, por exemplo, do que a escola, a comunidade, o professor entendem como educação.

A título de evidenciação do argumento ora apresentado e considerando a perspectiva interacionista, crítica e em acordo com o Paradigma da Comunicação, explicitamos as concepções orientadoras de uma prática pedagógica, ao nosso ver, no mínimo, coerente. Para tanto, apresentamos as concepções de educação, escola, aula, conhecimento e uma caracterização do professor condizente com o cenário descrito.

Entende-se educação como a interação entre sujeitos, assim constituídos porque autônomos no uso que fazem da linguagem, meio articulador destes sujeitos. É uma proposta de conhecer cuja orientação é prospectiva, visa ao projeto de futuros conhecimentos, o que ainda se pode aprender tendo como horizonte a emancipação. Em suma, educar é interagir, conhecer juntos, constituir-se sujeito social e politicamente emancipado.

Para tanto, o espaço formal da educação, a escola, precisa ser o encontro entre cidadãos para dialogarem sobre o mundo, sobre si e sobre suas demandas. Enquanto local formado por pessoas organizadas, possui uma intencionalidade que deve estar clara a todos os participantes. É o local onde se produzem conhecimentos e onde se convive com a pluralidade cultural. Da mesma forma, é um dos espaços sociais para a convivência e para a produção da cultura. Diferentemente do que nos fez crer a 
Pedagogia Tradicional, a função da escola não é ensinar, mas inserir na dinâmica das aprendizagens: o contínuo aprender a aprender.

A aula não é apenas o espaço físico, a sala de aula, mas o espaço das inter-relações, das intersubjetividades. A aula pode acontecer em qualquer lugar onde se proponha a produção do saber mediada pela linguagem, portanto, aula não é característica única da escola, produzir saberes acontece para além do espaço escolar.

O conhecimento implica sempre em relação social, em última análise, em aula como aqui a concebemos, implica vida e experiência. Conhecer tem um caráter provisório, pois tudo que é conhecido pode ser re-conhecido, re-aprendido, re-configurado mediante novas relações intersubjetivas.

Em acordo com esta seqüência de concepções, o professor é aquele que professa algo que acredita ser verdadeiro, útil e necessário aos estudantes e à sociedade. Ser professor é educar e só educa quem está no lugar de educar. Por isto, o professor é um sujeito (assim como o aluno), pois produz seu conhecimento também na pesquisa, entendida como um fundamento pedagógico. Considerando as concepções de aula, conhecimento, o professor precisa pesquisar, tematizar, problematizar a fim de modificar a situação genérica atual em que professores não produzem o conhecimento com o qual trabalham e nem determinam as estratégicas práticas de ação. O papel do professor consiste em:

recriação do mundo, resgate da alegria, da auto-estima, da interação, lembrando sempre que se ensina também pelo exemplo;

ser mediador na produção de sentidos, daí a importância da pesquisa;

administrar, através da mediação, a aula, promovendo a produção de saberes.

Em função da necessidade de atender a estes papéis, o professor precisa se constituir no profissional reflexivo e da reflexão na ação, tendo a reflexão como fundamento de suas práticas, considerando-se que aquilo que o professor pensa sobre educação determina o que o professor faz em suas práticas pedagógicas. Perrenoud confirma esta afirmação:

A autonomia e a responsabilidade de um profissional dependem de uma grande capacidade de refletir em e sobre sua ação. Essa capacidade está no âmago do desenvolvimento permanente, em função da experiência de competências e dos saberes profissionais.

Por isso, a figura do profissional reflexivo está no cerne do exercício de uma profissão, pelo menos quando a consideramos sob o ângulo da especialização e da inteligência no trabalho. (2002, p.13)

Com o intuito de refletir sobre sua ação o professor precisa ter a pesquisa como constante fonte de produção de seu saber na docência e a partir dela. Pesquisa constitui-se em atividade caracterizada por ser dinâmica, investigação do real, produção efetiva de saberes. Assiduamente trabalhando, auxiliado por seu grupo de colegas-professores, o professor vai aprendendo não só sobre o assunto de seu interesse, mas passa a tornar-se mais autônomo na pesquisa. Constituir-se pesquisador é a difrença entre um professor capaz de praticar a docência e refletir sobre sua prática e um professor alienado em sua própria prática, reproduzindo modelos sem refletir, agindo a partir de pressupostos alheios à sua realidade e ao seu fazer. 


\section{UMA CONCLUSÃO A SER PRODUZIDA PELO LEITOR}

Como a proposta deste texto não se encerra com a conclusão, pois esta discussão precisa ser encaminhada nos coletivos de professores organizados, é melhor não concluir, deixar que a conclusão seja produzida pelo leitor e apenas ponderar sobre as questões aqui apresentadas.

A intenção, ao propor esta breve reflexão, é trazer à tona a necessidade de se refletir sobre as práticas pedagógicas entendendo-as em seus pressupostos, as orientações determinantes deste ou daquele caminho na escola. Conforme Perrenoud:

(...) o paradigma reflexivo é um emblema da profissionalização, entendida como um poder dos professores sobre seu trabalho e sua organização, um poder não usurpado pela fragilidade das práticas, mas abertamente assumido, com as correspondentes responsabilidades. Essa forma de profissionalização, naturalmente, não pode se desenvolver contra as instituições. Mas elas só se manifestarão se um crescente número de professores assumir-se como profissional reflexivo (...) (2002, p.216)

É desta reflexão que nasce o necessário clareamento dos propósitos definidores da intencionalidade e capazes de dimensionar as transformações visando à constituição de um projeto efetivamente político e, por isto, consciente, para a escola e a prática educativa. Uma ação como esta reconfigura o professor, levando-o a exercer sua função de gestor de sua própria prática, um agente histórico, intelectual e profissional.

Refletindo sobre as orientações que determinam as práticas é possível propiciar ao professor a reconstituição de seu lugar: o lugar de educador que, ao promover educação também se educa. Quem sabe assim chega-se àquele ideal de educação, a tanto tempo buscado: educar para a autonomia, para lidar com o conhecimento e para saber resolver problemas hoje e para saber resolvê-los amanhã.

\section{REFERÊNCIAS BIBLIOGRÁFICAS}

FERREIRA, Liliana S. Educação \& História. Ijuí, Editora Unijui, 2001.

MARQUES, Mario Osorio. Conhecimento e modernidade em reconstrução. ljuí, Editora Unijui, 1993.

PERRENOUD, Philippe. A prática reflexiva no ofício de professor: profissionalização e razão pedagógica. Porto Alegre, Artmed, 2002.

PRESTES, Nadja Hermann. Educação e racionalidade: conexões e possibilidades de uma razão comunicativa na escola. Porto Alegre, EDPUCRS, 1996. 